\title{
Increased rate of reoperation in atypical femoral fractures is related to patient characteristics and not fracture type. A nationwide cohort study
}

\author{
H.P. Bögl ${ }^{1,2}$ (D) K. Michaëlsson ${ }^{3}$ (D) G. Zdolsek $^{2}$ (D) J. Höijer ${ }^{3}$ (D) J. Schilcher ${ }^{2}$ (D)
}

Received: 7 June 2019 / Accepted: 25 November 2019/Published online: 13 January 2020

(C) The Author(s) 2020

\begin{abstract}
Summary Atypical femoral fractures are burdened with a high rate of reoperation. In our nationwide analysis, the increased rate of reoperation was related to patient background characteristics, such as age and health status, rather than fracture type.

Introduction Patients with atypical fractures are complex to treat and burdened with a high risk of reoperation. We hypothesized that patients with surgically treated, complete atypical fractures have a higher risk of any reoperation and reoperation related to healing complications than patients with common femoral shaft fractures but that this increase would become insignificant when adjusted for predefined characteristics.

Methods A cohort of 163 patients with atypical fractures and 862 patients with common femoral shaft or subtrochanteric fractures treated from 2008 to 2010 and who had follow-up radiographs and register data available until 31 December 2014 was included. Reoperations were identified by a complementary review of radiographs and register data and were used to calculate risks for any reoperation and reoperations related to healing complications.

Results Patients with atypical fractures were more likely to be reoperated for any reason, age-adjusted OR 1.76 (95\% CI, 1.08 to 2.86). However, patients with common fractures had a shorter follow-up due to a threefold higher death rate. Accordingly, in a multivariable-adjusted time-to-event model, the increased risk lost statistical significance for any reoperations, cause-specific $\mathrm{HR}$ 1.34 ( $95 \% \mathrm{CI}, 0.85$ to 2.13), and for reoperations related to healing complications, HR 1.32 (95\% CI, 0.58 to 3.0). Continued use of bisphosphonate in the first year after the fracture did not affect the reoperation rate.

Conclusions Our findings suggest that the increased risk of reoperation after an atypical femur fracture is largely explained by patient characteristics and not fracture type.
\end{abstract}

Keywords Atypical femoral fracture $\cdot$ Bisphosphonates $\cdot$ Complications $\cdot$ Osteoporosis $\cdot$ Reoperation risk

Electronic supplementary material The online version of this article (https://doi.org/10.1007/s00198-019-05249-3) contains supplementary material, which is available to authorized users.

H.P. Bög1

hans.peter.bog1@ regiongavleborg.se

1 Department of Orthopedic Surgery, Gävle Hospital, Lasarettsvägen 5, SE-80324 Gävle, Sweden

2 Department of Orthopedics and Experimental and Clinical Medicine, Faculty of Health Science, Linköping University, Linköping, Sweden

3 Section of Orthopedics, Department of Surgical Sciences, Uppsala University, Uppsala, Sweden

\section{Introduction}

Despite the moderate absolute risk of a bisphosphonate user to suffer an atypical fracture [1], the patient and physician's fear of atypical fractures seems to have contributed to a recent decline in prescription rates for antiresorptives [2]. The common notion that atypical fractures are associated with a high risk of perioperative complications and a higher risk of delayed healing or non-union as well as consequential reoperations might have reinforced those fears [3-8]. The perception of a poor healing capacity is based on case reports $[9,10]$ and case series $[5,6$, 11-13], which contrast results from animal and human studies showing no negative impact of bisphosphonates on fracture healing, except for callus remodeling $[14,15]$. In long-term bisphosphonate exposure, the severe suppression of bone turnover has been suggested to decrease the anabolic response of 
the skeleton leading to impaired fracture healing [6]. However, because the local healing capacity in the cortical bone of patients treated with surgical resection of an incomplete AFF (stress fracture that has not yet broken completely) appears normal [16], impairment of fracture healing is even less likely for the healing of complete AFFs [17]. Case studies reporting an increased risk of healing complications might have been distorted by other factors (e.g., patient background characteristics, drug treatment [18], and death [19]) rather than the atypical fracture itself and associated bisphosphonate treatment.

Radiographic evaluation of fracture healing is inconsistent, especially in a retrospective study design [20]. Reoperations, on the other hand, can be objectively recorded. Our primary aim was to test the hypothesis that the proposed increased risk of reoperation and specifically the increased risk for reoperations related to complicated fracture healing will disappear in a time-to-event analysis after consideration of differences in patient background characteristics. A secondary aim was to analyze the effect modification of use or non-use of bisphosphonates before and after an atypical fracture on the rate of reoperation.

\section{Materials and methods}

\section{Study population}

In this nationwide cohort study comprising patients with either complete atypical or common low-energy subtrochanteric and femoral shaft fractures, we recorded all reoperations after the initial fracture. Reoperations related to healing complications were identified and used as a proxy variable for delayed or non-healing.

All patients $\geq 55$ years who were treated as inpatients for a fractured femur between 2008 and 2010 were identified through the Swedish National Inpatient Register (Fig. 1). We only included patients if the fracture was located in the subtrochanteric or diaphyseal region as defined by ICD-10 codes (International Classification of Diseases, 10th Revision [ICD-10]) in the register (diagnosis code S722 or S723) and only fractures associated with low-energy trauma (external cause code W [i.e., excluding any type of transportation accident]). In cases of bilateral fractures, only the first was included to avoid selection bias.

This patient cohort has been investigated previously [1] and includes 5475 patients in a nationwide population of 2,891,586 women and men in Sweden. Of these 5475 patients, 4351 omitted because the location or nature of the fracture excluded an atypical fracture or rendered the fracture inappropriate for comparison with atypical fractures. The majority of these patients had pertrochanteric femur fractures erroneously coded as subtrochanteric femur fractures and implants in the ipsilateral femur. The original cohort that served as the source for this investigation included 1124 patients (Fig. 1) $[1,21]$.

\section{Fracture types}

Atypical fractures were classified based on radiographic criteria of the revised version of the American Society of Bone and Mineral Research (ASBMR) task force criteria [3]. A transverse fracture line originating from the lateral side and focal cortical thickening at the fracture site were compulsory criteria $[1,3,17$, 22]. Fractures were registered as either subtrochanteric (tip of the lesser trochanter and $5 \mathrm{~cm}$ distal to it) or diaphyseal (to the supracondylar flare) [23]. Common fractures (CFFs) were defined as spiral, oblique, or comminute fractures [3]. Only complete fractures were included. Both reviewers (GZ, HPB) were blinded to all background information. The final classification into fracture types was based on the previous classification [1].

\section{Identification of reoperations}

We used two complementary approaches to identify reoperations.

First, we retrieved all radiographic images (including magnetic resonance) of the affected femur from all radiology departments throughout Sweden $(n=76)$ between the date of the initial fracture and 31 December 2014. All images were screened for any changes in the morphology of the bone, the fracture and fixation devices indicating that a reoperation might had been performed. Among all reoperations, we identified those related to a complicated course of healing (Table 3) where at least one of the following radiographic signs was present: incomplete obliteration of the fracture line, incomplete cortical continuity, or implant failure. In patients who had undergone multiple reoperations, only the most complex reoperation was used in the statistical analyses to reflect the most relevant clinical impact for the patient. Dynamization procedures were not considered as reoperations due to healing complications because there is no high-quality evidence to support dynamization as a means to improve fracture healing [24-26]. The time interval between the initial fracture and the main reoperation was calculated in days. We excluded 99 patients from the original cohort of 1124 patients because of incomplete radiographic imaging $(n=51)$, preexistent implants $(n=39)$, or other reasons $(n=9)$.

In a second step, we retrieved data from the Swedish National Patient Register (NPR) on every admission for each individual patient from the initial fracture admission until 31 December 2014. We only considered admissions with the discharge diagnosis S72, T84, T81, T93, M84, M80.9, and M96, combined with a surgical procedure code of the Swedish version of the NOMESCO classification of surgical procedures 


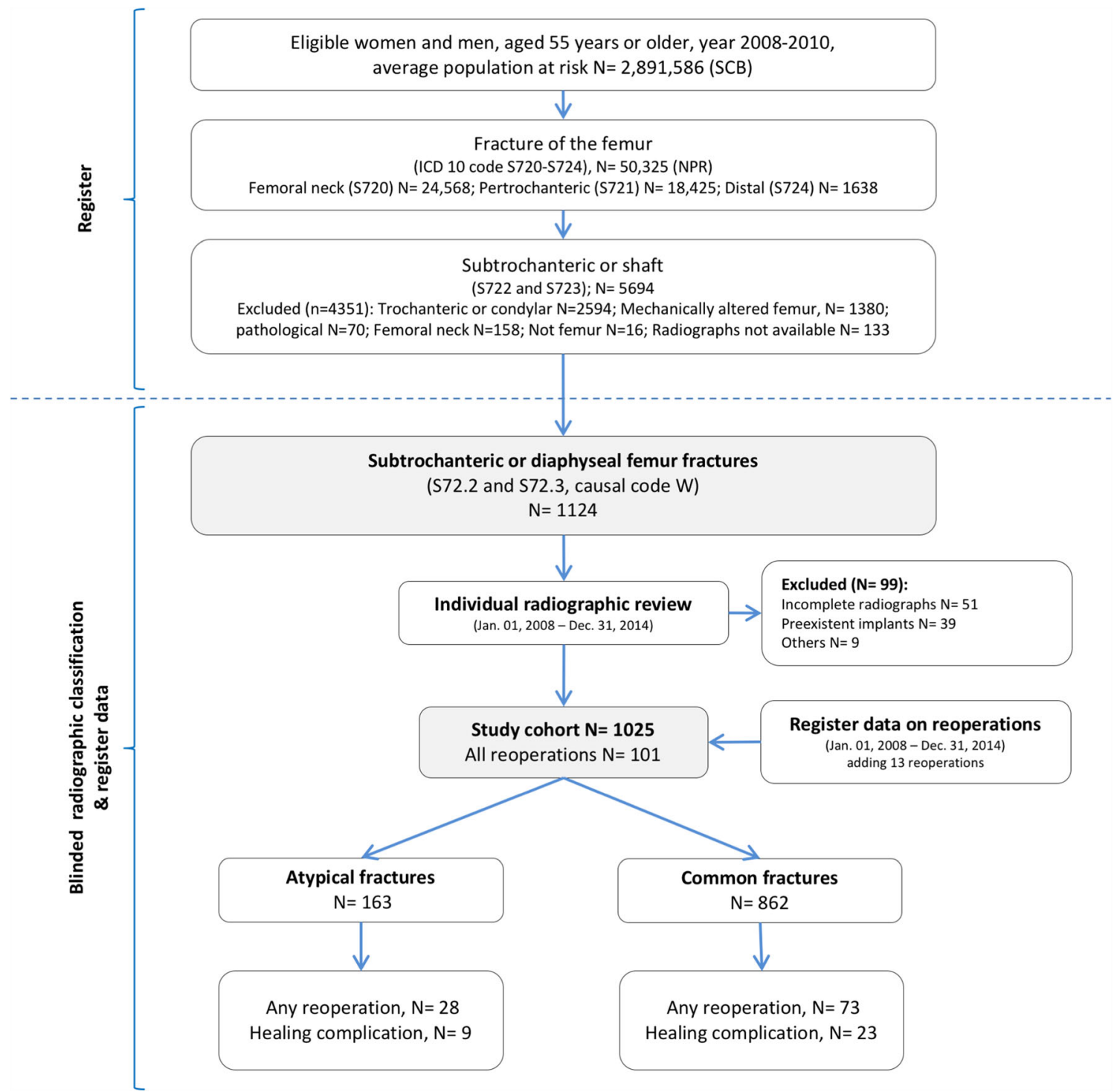

Fig. 1 Patient selection and identification of reoperations based on individual radiographic review and data from national registers (from 1 January 2008 to 31 December 2014). SCB: Statistics Sweden.

Mechanically altered femur: preexisting implants, underlying bone conditions altering skeletal biomechanics (i.e. previous fractures, Paget's disease of the bone, tumours, etc.)

(Supplementary Table 1). The comparison with register data yielded another 13 reoperations $(\mathrm{AFF}=3, \mathrm{CFF}=10)$. These reoperations included 10 screw removals, one arthroscopy, one reoperation due to hemorrhage, and one unspecified reoperation. The final study cohort included 1025 patients $(\mathrm{AFF}=163 ; \mathrm{CFF}=862)$.

\section{Registers}

In Sweden, all permanent residents are provided a unique personal identification number that allows complete linkage with all nationwide registers. Data on drug use were obtained from the Swedish Prescribed Drug Register [1, 21], including data on dispensing of bisphosphonates and oral corticosteroids before and after the fracture admission [19]. Drug treatment

was defined as ever use. Discharge diagnoses were collected from the NPR from 1987 and for outpatient visits from 2001 until 31 December 2014 [1,21]. Depending on type, the positive predictive value of diagnoses registered in the NPR ranges from 85 to $100 \%$ [27]. All diagnoses before the date of the fracture were included to calculate the individual weighted Charlson's comorbidity index at baseline [28].

We determined dates of death after fracture events by linkage to the National Population Register of the Swedish Tax Agency. Calculated from the period of inclusion (years 2008 through 2010), the mortality rate was determined for up to 7 years (until 31 December 2014) after the fracture event. The study was approved by the regional ethical review board in Linköping, (DNR 2014/407-31, 2015/382-32). 


\section{Statistical analysis}

The risk of reoperation was calculated for each fracture type. Furthermore, age-adjusted odds ratios (ORs, using unconditional logistic regression) and relative risks (RRs, using logbinomial regression) were calculated separately for any type of reoperation and those related to healing complications. Odds ratios and relative risks were then further adjusted for the following predefined variables: sex, Charlson's comorbidity index, and corticosteroid treatment. In addition to risk assessments, we performed time-to-event analysis using Cox regression to estimate age and multivariable-adjusted causespecific hazard ratios (csHRs) for any type of reoperation and those related to healing complications. Age-standardized incidence rates were calculated, by use of direct standardization and five-year age intervals, with the age distribution of CFF patients as a reference.

We used the group of patients with CFF as a control group because they were representative of the general population of patients with underlying vulnerability to fractures and refrained from matching to avoid the introduction of selection bias [29].

We performed competing risk analysis (as a sensitivity analysis) with death as the competing event due to known differences in mortality rate [19].

We additionally used stratified analyses to estimate the impact of use and non-use of bisphosphonates on the hazard for reoperation. Stratified multivariable-adjusted csHRs were calculated and are presented as a forest plot (Fig. 2). Stata (version 15) and IBM SPSS (version 25) were used for statistical analyses.

\section{Results}

Patient and implant characteristics are listed in Tables 1 and 2.

\section{Reoperations}

Any type of reoperation was performed in $28(17 \%)$ patients with AFFs and in 73 (8\%) with CFFs (Table 3). Reoperations related to healing complications were done in 9 patients with AFFs and in 23 with CFFs. Multiple reoperations were performed in 20 patients ( $8 \mathrm{AFF}$, and $12 \mathrm{CFF}$ ). The age-adjusted RR was 1.61 (95\% CI, 1.07 to 2.43 ) for any reoperation and 1.69 ( $95 \% \mathrm{CI}, 0.78$ to 3.68 ) for reoperations related to healing complications. When further corrected for differences in the predefined variables (i.e., sex, Charlson's comorbidity index, corticosteroid treatment), the RRs were attenuated to 1.41 (95\% CI, 0.92 to 2.17) for any reoperation and to 1.41 (95\% CI, 0.63 to 3.17 ) for reoperations related to healing complications.

Adjusting for differences in follow-up time and accordingly unequal death rates (19\% vs. $58 \%$ in patients with common fractures), the multivariable-adjusted csHR for any reoperation was 1.34 (95\% CI, 0.85 to 2.13). A similar HR, though with lower precision, was calculated for reoperations related to healing complications as outcome. Expectedly, the subdistribution HRs for a reoperation were quite similar to the relative risk estimates (Table 4).

Of the 163 patients with atypical fracture, 127 (78\%) had received bisphosphonate treatment before the index fracture. Of the bisphosphonate users, 17 (13\%) were reoperated for any reason; of the bisphosphonate non-
Fig. 2 Stratified, multivariableadjusted cause-specific hazard ratios ( $x$-axis) for any reoperation

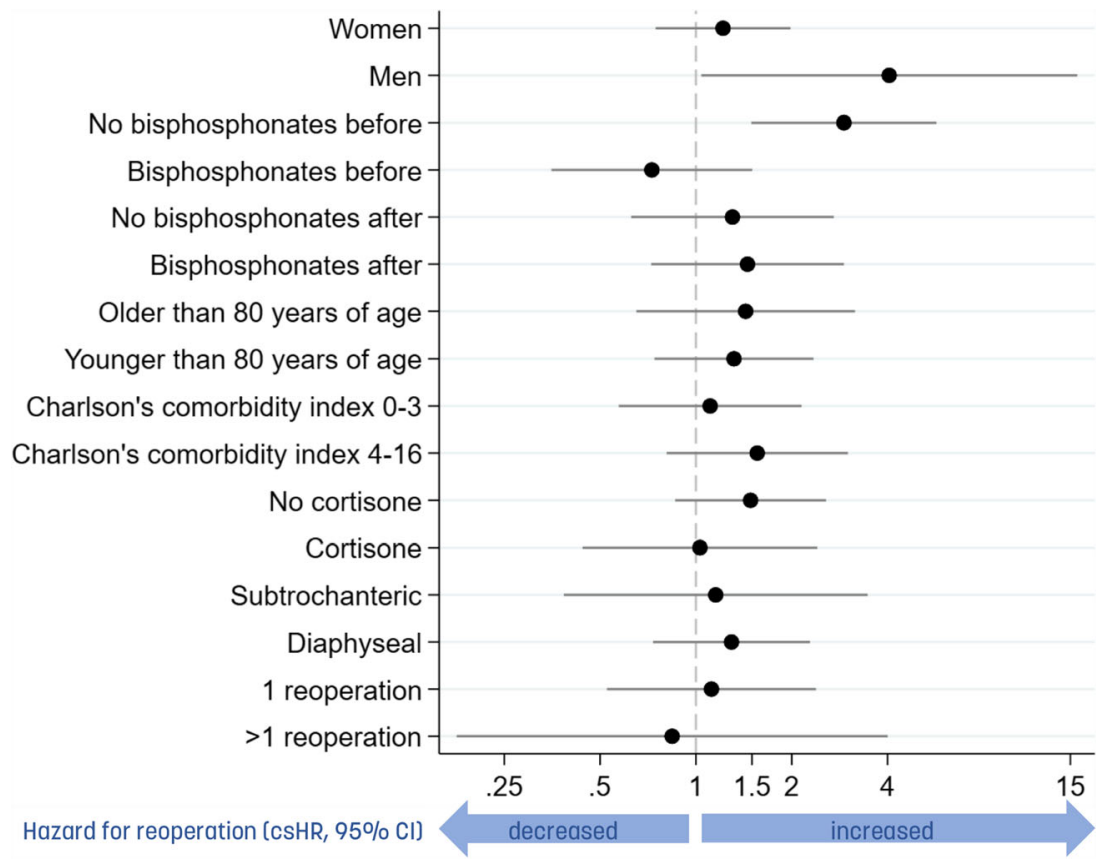


Table 1 Patient background characteristics

\begin{tabular}{|c|c|c|c|}
\hline & & AFF & CFF \\
\hline \multicolumn{2}{|l|}{$\mathrm{N}$} & 163 & 862 \\
\hline \multicolumn{2}{|l|}{ Age, mean (SD) } & $76.6(8.19)$ & $82.2(9.58)$ \\
\hline \multirow[t]{2}{*}{ Sex } & Male & $11(6.7 \%)$ & $169(19.6 \%)$ \\
\hline & Female & $152(93.3 \%)$ & $693(80.4 \%)$ \\
\hline \multicolumn{2}{|c|}{ Charlson's comorbidity index, median (IQR) } & $3(1-5)$ & $3(1-6)$ \\
\hline \multicolumn{2}{|c|}{ Time to complication (years) ${ }^{1}$, median (IQR) } & $0.74(0.46-1.2)$ & $0.64(0.19-1.3)$ \\
\hline \multirow[t]{3}{*}{ Outcome } & No event & $104(63.8 \%)$ & $290(33.6 \%)$ \\
\hline & Reoperation & $28(17.2 \%)$ & $74(8.6 \%)$ \\
\hline & Death & $31(19.0 \%)$ & $498(57.8 \%)$ \\
\hline \multicolumn{2}{|c|}{ Time to death (years) ${ }^{2}$, median (IQR) } & $2.8(1.9-4.2)$ & $1.9(0.4-3.4)$ \\
\hline \multicolumn{2}{|c|}{ Follow-up time (years), median (IQR) } & $4.5(2.7-5.5)$ & $3.2(0.9-4.9)$ \\
\hline \multicolumn{2}{|c|}{ Bisphosphonate use before the fracture } & $127(77.9 \%)$ & $102(11.8 \%)$ \\
\hline \multicolumn{2}{|c|}{$\begin{array}{l}\text { Bisphosphonate use after the fracture } \\
\text { (first year) }\end{array}$} & $110(67.5 \%)$ & $127(14.7 \%)$ \\
\hline \multicolumn{2}{|c|}{$\begin{array}{l}\text { Bisphosphonate use before fracture. } \\
\text { Duration (years), mean (SD) }\end{array}$} & $3.64(1.1)$ & $2.34(1.65)$ \\
\hline \multicolumn{2}{|c|}{ Corticosteroid use } & $49(30.1 \%)$ & $140(16.2 \%)$ \\
\hline \multirow[t]{2}{*}{ Fracture location } & Subtrochanteric & $25(15.3 \%)$ & $559(64.8 \%)$ \\
\hline & Diaphyseal & $138(84.7 \%)$ & $303(35.2 \%)$ \\
\hline
\end{tabular}

${ }^{1}$ For those with complication; ${ }^{2}$ For those who died during observation interval

users, $11(31 \%)$ were reoperated for any reason: multivariable-adjusted csHR $0.34(95 \% \mathrm{CI}, 0.14$ to $0.81)$. The rate remained lower even when reoperations related to healing complications were compared: multivariable-adjusted csHR 0.13 (95\% CI, 0.03 to 0.54 ).

In contrast to patients with atypical fractures, bisphosphonate users who had had a common fracture displayed an increase in the rate of reoperations related to healing complications, with a multivariable-adjusted csHR of 2.62 (95\% CI, 1.03 to 6.68). The multivariable-adjusted csHR for any type of reoperation was 1.65 (95\% CI, 0.92 to 2.98). Continued use of bisphosphonate in the first year after the index fracture was not associated with an increased risk of any type of reoperation, regardless of fracture type.

Table 2 Frequencies of implants used

\begin{tabular}{|c|c|c|c|c|c|c|}
\hline \multirow[t]{2}{*}{ Implant } & \multicolumn{2}{|c|}{ AFF } & \multicolumn{2}{|l|}{$\mathrm{CFF}$} & \multicolumn{2}{|l|}{ Total } \\
\hline & $N$ & $\%$ & $N$ & $\%$ & $\mathrm{~N}$ & $\%$ \\
\hline AFN & 138 & 84.7 & 616 & 71.5 & 754 & 73.6 \\
\hline RFN & 22 & 13.5 & 121 & 14.0 & 143 & 14.0 \\
\hline Plate* & 3 & 1.8 & 125 & 14.5 & 128 & 12.5 \\
\hline Total & 163 & 100 & 862 & 100 & 1025 & 100 \\
\hline
\end{tabular}

AFN antegrade femoral nail, RFN retrograde femoral nail

*any type of plate construct

\section{Discussion}

Consistent with our hypothesis, age-adjusted estimates showed an increased risk of reoperation in patients with atypical femoral fractures. This risk difference became substantially attenuated when predefined patient background characteristics and follow-up time were controlled.

Impaired fracture healing is one of the proposed clinical hallmarks of AFFs and was adopted as a minor criterion in the first ASBMR task force report [3]. Numerous case reports have described increased reoperation rates after an atypical fracture [5, 10, 30-33], in one study as high as $46 \%$ [11]. The criterion of delayed healing mainly referred to incomplete AFFs (stress fractures), with inhibition of direct bone healing (inhibition of targeted remodeling) suggested as a possible mechanism. This seems reasonable, because bisphosphonate treatment in animal models has shown accumulation of microdamage formation [34] and inhibited resorption of fracture surfaces in stress fractures [35]. Inhibited resorption was coupled with impairment of new bone formation thus leading to delayed fracture healing [34, 35]. However, when incomplete atypical fractures are excised by use of a full-thickness cortical bone biopsy, the cortical defect that remains heals by indirect fracture healing and the formation of new bone occurs at normal speed, despite long-term bisphosphonate treatment [16]. This is not surprising because in indirect fracture healing, with the formation of an external callus, bone formation is uncoupled from bone resorption. This type of fracture healing therefore is typically not affected by bisphosphonates [15]. The remodeling of the external callus on 
Table 3 Frequencies and types of reoperations

\begin{tabular}{llcc}
\hline Type of reoperation & & AFF $(N=163)$ & CFF $(N=862)$ \\
\hline Reoperations related to healing complication & Revision from intramedullary nail to plate & 1 & 8 \\
& Revision from plate to intramedullary nail & 1 & 5 \\
& Intramedullary nail exchange & 7 & 7 \\
Other reoperations & Hip arthroplasty in presence of non-union & 0 & 12 \\
& Partial implant removal & 2 & 5 \\
& Complete implant removal & 6 & 3 \\
& Dynamization procedure & 8 & 21 \\
Total & Peri-implant fractures & 0 & 2 \\
& Hip arthroplasty due to osteoarthritis & 1 & 7 \\
& Other & 28 & 73
\end{tabular}

the other hand is delayed by bisphosphonates, because it involves osteoclast-derived resorption of callus tissue followed by lamellar bone formation through osteoblasts. Complete atypical fractures heal through the mechanism of indirect fracture healing, which supports our hypothesis that healing of complete atypical fractures should not be affected by bisphosphonate treatment.

In more recent reports, rates of reoperation in AFFs are much lower, especially with the use of cephalomedullary nails $[7,8$, $13,36,37]$. Nonetheless, these recent reports describe a delayed union when using historic controls or the use of the conventional 6 months as the cut-off point for delayed healing [8, 38]. One study found an increased risk of complicated healing in AFF patients compared with controls, even when delayed healing was based not only on radiographic but also clinical signs [39]. Risk estimates in that study, however, were not corrected for differences in patient background characteristics. The inability to correct for differences in patient background characteristics is a potential shortcoming in previous reports comparing outcomes of AFFs with other fracture types. In our study, we were not able to directly evaluate differences in fracture healing and instead used reoperations associated with complicated fracture healing as an indirect measure. The use of this proxy might introduce selection bias because the true number of patients with complicated healing remains unknown and might differ between groups. Given the retrospective design, we were not able to validate this proxy or directly control for it. However, in contrast to previous reports, we were able to control for multiple confounding factors and survival time, by using adjusted risk and time-to-event analyses with correction of predefined variables. With these adjustments, differences in reoperation rates associated with complicated healing were modest.

For a number of reasons, reoperation rates could conceivably differ between the two fracture groups. Patients with atypical fractures might expose the implant to greater stress during the period of fracture healing because of their younger age and more active lifestyle [7, 40]. This selection might be an effect of drug channeling bias as a consequence of treating younger and healthier patients with bisphosphonates [41]. On the contrary, elderly patients with common fractures might not seek health care for a non-union or might be deemed unfit to undergo surgery. Such an effect is conceivable considering that more than half of the patients with common fractures died during the 4-7-year follow-up.

We observed a lower risk of reoperations in patients with atypical fractures treated with bisphosphonates compared with those without treatment, even in the multivariable-adjusted model. Little is known about this subgroup of patients expressing radiologic features of atypical fractures but without reported use of bisphosphonate. One possible explanation could be that patients without a history of bisphosphonate treatment suffer from undetected bone metabolic conditions with a predisposition for stress fractures and impaired fracture healing. Further investigations are needed to elucidate these differences. Continuation of bisphosphonate therapy during the first year after the fracture did not influence the risk of reoperation comparing atypical fractures with common fractures. These findings are in line with previous results [7]. A shorter treatment duration before the fracture has been suggested to decrease the risk of complicated healing $[38,39,42]$. However, sample sizes were small in those studies [38].

A main strength of our study is the nationwide coverage and complete linkage between high-quality registers and radiographic adjudication of fracture site and features in accordance with current ASBMR criteria and our rigorous identification of reoperations, using two complementary methods. Limitations include the observational study design and the potential for residual confounding or undetected selection mechanisms related to fragility not captured by our study design. Differences in such factors between the two fracture types would probably result in further attenuation of our estimates. Because the majority of the patients in our cohort are of Caucasian origin, our results should be extrapolated to other ethnic groups with some reservation, especially given that atypical fractures are coupled to ethnicity and biomechanical aspects of femoral geometry 


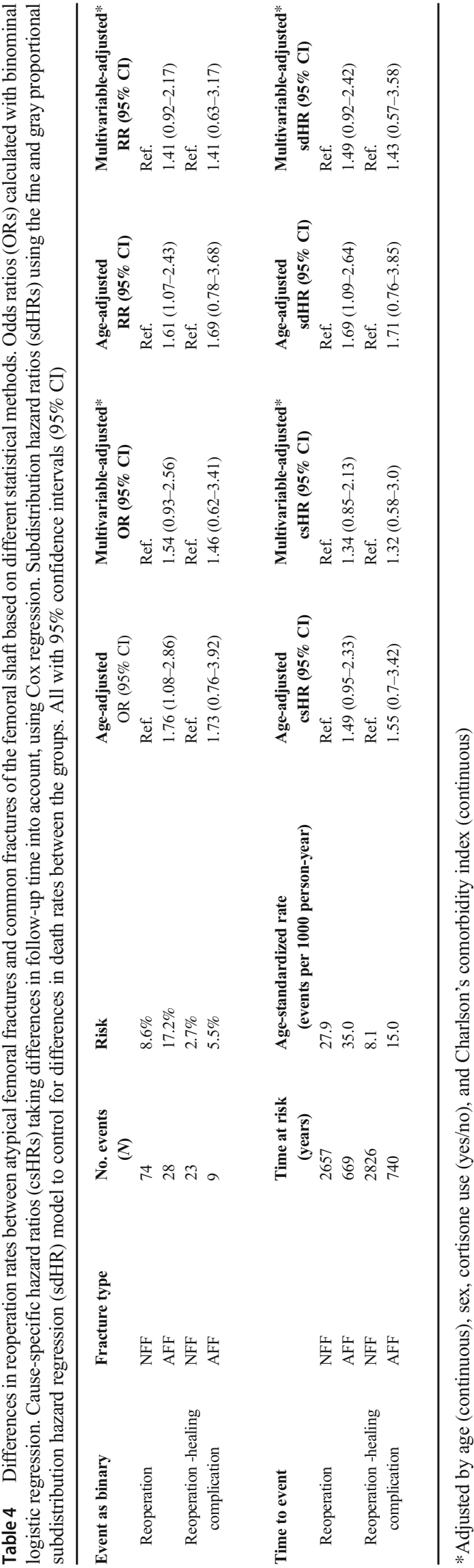

$[43,44]$. Patients in both groups were treated with different surgical techniques and implants. It is possible that some implants might be more beneficial depending on the fracture configuration. Such comparisons were beyond the scope of this study. Despite a relatively large number of patients in our cohort, the proportion of patients with complications was about $10 \%$, resulting in a moderate precision of our estimates.

The results of our study confirm an increased risk of reoperation for patients with atypical fractures. However, it appears that patient-related factors such as health status and survival have a stronger impact on the reoperation risk than the type of fracture.

Acknowledgements Open access funding provided by Linköping University. The authors would like to thank Per Aspenberg and all radiology departments throughout the country for their intellectual contributions and support.

Funding information The study was funded by a research grant from ALF Grants (Avtal om läkarutbildning och forskning), Östergötland County Council, Sweden (grant number: LIO-698411).

Hans Peter Bögl received grants from Region Gävleborg for doctoral studies (grant number: CFUG-651191).

\section{Compliance with ethical standards}

Conflicts of interest None.

Open Access This article is licensed under a Creative Commons Attribution-NonCommercial 4.0 International License, which permits any non-commercial use, sharing, adaptation, distribution and reproduction in any medium or format, as long as you give appropriate credit to the original author(s) and the source, provide a link to the Creative Commons licence, and indicate if changes were made. The images or other third party material in this article are included in the article's Creative Commons licence, unless indicated otherwise in a credit line to the material. If material is not included in the article's Creative Commons licence and your intended use is not permitted by statutory regulation or exceeds the permitted use, you will need to obtain permission directly from the copyright holder. To view a copy of this licence, visit http://creativecommons.org/licenses/by-nc/4.0/.

\section{References}

1. Schilcher J, Koeppen V, Aspenberg P, Michaelsson K (2015) Risk of atypical femoral fracture during and after bisphosphonate use. Acta Orthop 86:100-107

2. Jha S, Wang Z, Laucis N, Bhattacharyya T (2015) Trends in media reports, oral bisphosphonate prescriptions, and hip fractures 19962012: an ecological analysis. J Bone Miner Res 30:2179-2187

3. Shane E, Burr D, Abrahamsen B et al (2014) Atypical subtrochanteric and diaphyseal femoral fractures: second report of a task force of the American Society for Bone and Mineral Research. J Bone Miner Res 29:1-23

4. Edwards BJ, Bunta AD, Lane J, Odvina C, Rao DS, Raisch DW, McKoy J, Omar I, Belknap SM, Garg V, Hahr AJ, Samaras AT, Fisher MJ, West DP, Langman CB, Stern PH (2013) Bisphosphonates and nonhealing femoral fractures: analysis of the FDA adverse event reporting system (FAERS) and international safety 
efforts: a systematic review from the research on adverse drug events and reports (RADAR) project. J Bone Joint Surg Am 95:297-307

5. Ing-Lorenzini K, Desmeules J, Plachta O, Suva D, Dayer P, Peter R (2009) Low-energy femoral fractures associated with the long-term use of bisphosphonates. Drug Saf 32:775-785

6. Odvina CV, Zerwekh JE, Rao DS, Maalouf N, Gottschalk FA, Pak CY (2005) Severely suppressed bone turnover: a potential complication of alendronate therapy. J Clin Endocrinol Metab 90:1294-1301

7. Bogdan Y, Tornetta P 3rd, Einhorn TA et al (2016) Healing time and complications in operatively treated atypical femur fractures associated with bisphosphonate use: a multicenter retrospective cohort. J Orthop Trauma 30:177-181

8. Egol KA, Park JH, Rosenberg ZS, Peck V, Tejwani NC (2014) Healing delayed but generally reliable after bisphosphonateassociated complete femur fractures treated with IM nails. Clin Orthop Relat Res 472:2728-2734

9. O'Neill BJ, O'HEireamhoin S, Morrissey DI, Keogh P (2014) Implant failure caused by non-union of bisphosphonate-associated subtrochanteric femur fracture. BMJ Case Rep 2014. https://doi. org/10.1136/bcr-2013-203519

10. Schneider JP (2006) Should bisphosphonates be continued indefinitely? An unusual fracture in a healthy woman on long-term alendronate. Geriatrics 61:31-33

11. Weil YA, Rivkin G, Safran O, Liebergall M, Foldes AJ (2011) The outcome of surgically treated femur fractures associated with longterm bisphosphonate use. J Trauma 71:186-190

12. Teo BJ, Koh JS, Goh SK, Png MA, Chua DT, Howe TS (2014) Postoperative outcomes of atypical femoral subtrochanteric fracture in patients on bisphosphonate therapy. Bone Joint J 96-B:658-664

13. Lee KJ, Yoo JJ, Oh KJ, Yoo JH, Rhyu KH, Nam KW, Suh DH (2017) Surgical outcome of intramedullary nailing in patients with complete atypical femoral fracture: a multicenter retrospective study. Injury 48:941-945

14. Kates SL, Ackert-Bicknell CL (2016) How do bisphosphonates affect fracture healing? Injury 47:S65-S68

15. Larsson S, Fazzalari NL (2014) Anti-osteoporosis therapy and fracture healing. Arch Orthop Trauma Surg 134:291-297

16. Bogl HP, Aspenberg P, Schilcher J (2017) Undisturbed local bone formation capacity in patients with atypical femoral fractures: a case series. Osteoporos Int 28:2439-2444

17. Schilcher J, Michaelsson K, Aspenberg P (2011) Bisphosphonate use and atypical fractures of the femoral shaft. N Engl J Med 364:17281737

18. Starr J, Tay YKD, Shane E (2018) Current understanding of epidemiology, pathophysiology, and management of atypical femur fractures. Curr Osteoporos Rep 16:519-529

19. Kharazmi M, Hallberg P, Schilcher J, Aspenberg P, Michaelsson K (2016) Mortality after atypical femoral fractures: a cohort study. J Bone Miner Res 31:491-497

20. Corrales LA, Morshed S, Bhandari M, Miclau T 3rd (2008) Variability in the assessment of fracture-healing in orthopaedic trauma studies. J Bone Joint Surg Am 90:1862-1868
21. Schilcher J, Koeppen V, Aspenberg P, Michaelsson K (2014) Risk of atypical femoral fracture during and after bisphosphonate use. N Engl J Med 371:974-976

22. Shane E (2010) Evolving data about subtrochanteric fractures and bisphosphonates. N Engl J Med 362:1825-1827

23. Fielding JW (1973) Subtrochanteric fractures. Clin Orthop Relat Res (92): 86-99. https://doi.org/10.1097/00003086-19730500000008

24. Wu CC (1997) The effect of dynamization on slowing the healing of femur shaft fractures after interlocking nailing. J Trauma 43:263-267

25. Wu CC, Chen WJ (1997) Healing of 56 segmental femoral shaft fractures after locked nailing. Poor results of dynamization. Acta Orthop Scand 68:537-540

26. Papakostidis C, Psyllakis I, Vardakas D, Grestas A, Giannoudis PV (2011) Femoral-shaft fractures and nonunions treated with intramedullary nails: the role of dynamisation. Injury 42:1353-1361

27. Ludvigsson JF, Andersson E, Ekbom A, Feychting M, Kim JL, Reuterwall C, Heurgren M, Olausson PO (2011) External review and validation of the Swedish national inpatient register. BMC Public Health 11:450

28. Quan H, Sundararajan V, Halfon P, Fong A, Burnand B, Luthi JC, Saunders LD, Beck CA, Feasby TE, Ghali WA (2005) Coding algorithms for defining comorbidities in ICD-9-CM and ICD-10 administrative data. Med Care 43:1130-1139

29. Mansournia MA, Jewell NP, Greenland S (2018) Case-control matching: effects, misconceptions, and recommendations. Eur J Epidemiol 33:5-14

30. Bunning RD, Rentfro RJ, Jelinek JS (2010) Low-energy femoral fractures associated with long-term bisphosphonate use in a rehabilitation setting: a case series. PM R 2:76-80

31. Visekruna M, Wilson D, McKiernan FE (2008) Severely suppressed bone turnover and atypical skeletal fragility. J Clin Endocrinol Metab 93:2948-2952

32. Sayed-Noor AS, Sjoden GO (2008) Subtrochanteric displaced insufficiency fracture after long-term alendronate therapy-a case report. Acta Orthop 79:565-567

33. Somford MP, Draijer FW, Thomassen BJ, Chavassieux PM, Boivin G, Papapoulos SE (2009) Bilateral fractures of the femur diaphysis in a patient with rheumatoid arthritis on long-term treatment with alendronate: clues to the mechanism of increased bone fragility. J Bone Miner Res 24:1736-1740

34. Barrett JG, Sample SJ, McCarthy J, Kalscheur VL, Muir P, Prokuski L (2007) Effect of short-term treatment with alendronate on ulnar bone adaptation to cyclic fatigue loading in rats. J Orthop Res 25:1070-1077

35. Kidd LJ, Cowling NR, Wu AC, Kelly WL, Forwood MR (2011) Bisphosphonate treatment delays stress fracture remodeling in the rat ulna. J Orthop Res 29:1827-1833

36. Khow KS, Paterson F, Shibu P, Yu SC, Chehade MJ, Visvanathan R (2017) Outcomes between older adults with atypical and typical femoral fractures are comparable. Injury 48:394-398

37. Schultz DS, Gass HM, Barfield WR, Demos HA, Hartsock LA (2018) Surgical complications associated with atypical femur fractures attributed to bisphosphonate use. J Surg Orthop Adv 27:14-20 
38. Thompson RN, Phillips JR, McCauley SH, Elliott JR, Moran CG (2012) Atypical femoral fractures and bisphosphonate treatment: experience in two large United Kingdom teaching hospitals. J Bone Joint Surg British 94:385-390

39. Lim SJ, Yeo I, Yoon PW, Yoo JJ, Rhyu KH, Han SB, Lee WS, Song JH, Min BW, Park YS (2018) Incidence, risk factors, and fracture healing of atypical femoral fractures: a multicenter case-control study. Osteoporos Int 29:2427-2435

40. Shkolnikova J, Flynn J, Choong P (2013) Burden of bisphosphonateassociated femoral fractures. ANZ J Surg 83:175-181

41. Abrahamsen B, Prieto-Alhambra D (2016) Patients with atypical femur fractures have the same mortality as the background population-drug-channeling bias, bisphosphonate effects, and public health implications. J Bone Miner Res 31:488-490
42. Kang JS, Won YY, Kim JO, Min BW, Lee KH, Park KK, Song JH, Kim YT, Kim GH (2014) Atypical femoral fractures after antiosteoporotic medication: a Korean multicenter study. Int Orthop 38:1247-1253

43. Schilcher J, Howe TS, Png MA, Aspenberg P, Koh JS (2015) Atypical fractures are mainly subtrochanteric in Singapore and diaphyseal in Sweden: a cross-sectional study. J Bone Miner Res 30:2127-2132

44. Lo JC, Hui RL, Grimsrud CD, Chandra M, Neugebauer RS, Gonzalez JR, Budayr A, Lau G, Ettinger B (2016) The association of race/ ethnicity and risk of atypical femur fracture among older women receiving oral bisphosphonate therapy. Bone 85:142-147

Publisher's note Springer Nature remains neutral with regard to jurisdictional claims in published maps and institutional affiliations. 